Supporting Information for

\title{
Analysis of Guest Adsorption on Crystal Surfaces Based on the Fragment Molecular Orbital Method
}

Taiji Nakamura, ${ }^{a}$ Tomoko Yokaichiya, ${ }^{a, b}$ Dmitri G. Fedorov ${ }^{a,}$ *

${ }^{a}$ Research Center for Computational Design of Advanced Functional Materials (CD-FMat), National Institute of Advanced Industrial Science and Technology (AIST), Central 2, Umezono 1-1-1, Tsukuba, 305-8568, Japan.

b Current address: Department of Chemical System Engineering, Graduate School of Engineering, the University of Tokyo, Hongo 7-3-1, Tokyo, 113-8656, Japan

* Corresponding author 
Table S1. Cell parameters for ice Ih crystals.

\begin{tabular}{|c|c|c|c|}
\hline & \multicolumn{3}{|c|}{ Hexagonal 1x1x1 elementary cell in crystal } \\
\hline & $a, \AA$ & $b, \AA$ & $c, \AA$ \\
\hline Experiment $(10 \mathrm{~K})^{1}$ & 4.49693 & 4.49693 & 7.32109 \\
\hline Simulation $^{2}$ & 4.5071 & 4.5069 & 7.3600 \\
\hline \multirow{2}{*}{$\begin{array}{l}\text { Computation, }{ }^{\text {a }} \\
\text { this work }\end{array}$} & 4.5135 & 4.5132 & 7.3610 \\
\hline & \multicolumn{3}{|c|}{ Orthogonal $3 \times 2 \times 2$ cell used for modeling adsorption } \\
\hline Simulation $^{2}$ & 13.52118 & 15.61292 & 14.72000 \\
\hline This work $^{\mathrm{a}}$ & 13.5406 & 15.6345 & 14.7220 \\
\hline
\end{tabular}

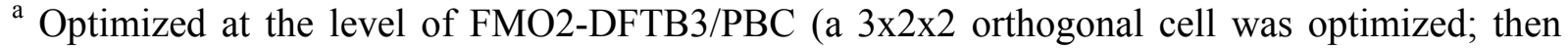
from it, hexagonal cell parameters were computed).

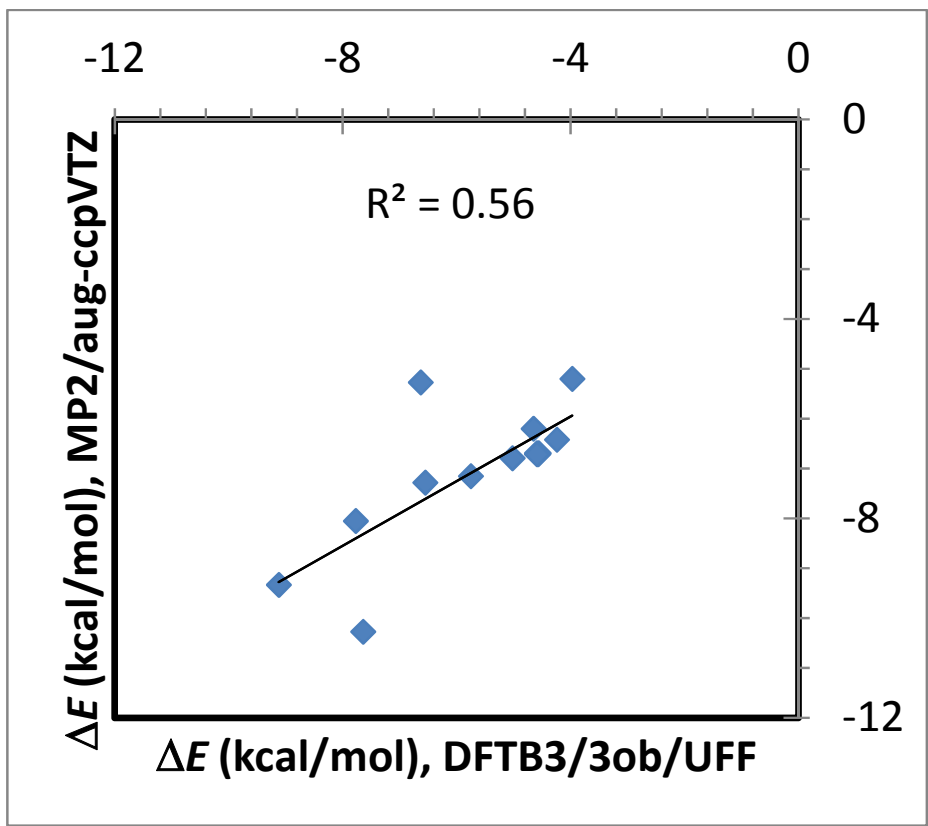

Figure S1. Binding energies $(\mathrm{kcal} / \mathrm{mol})$ in all binary complexes, with the data point for acetic acid removed. 

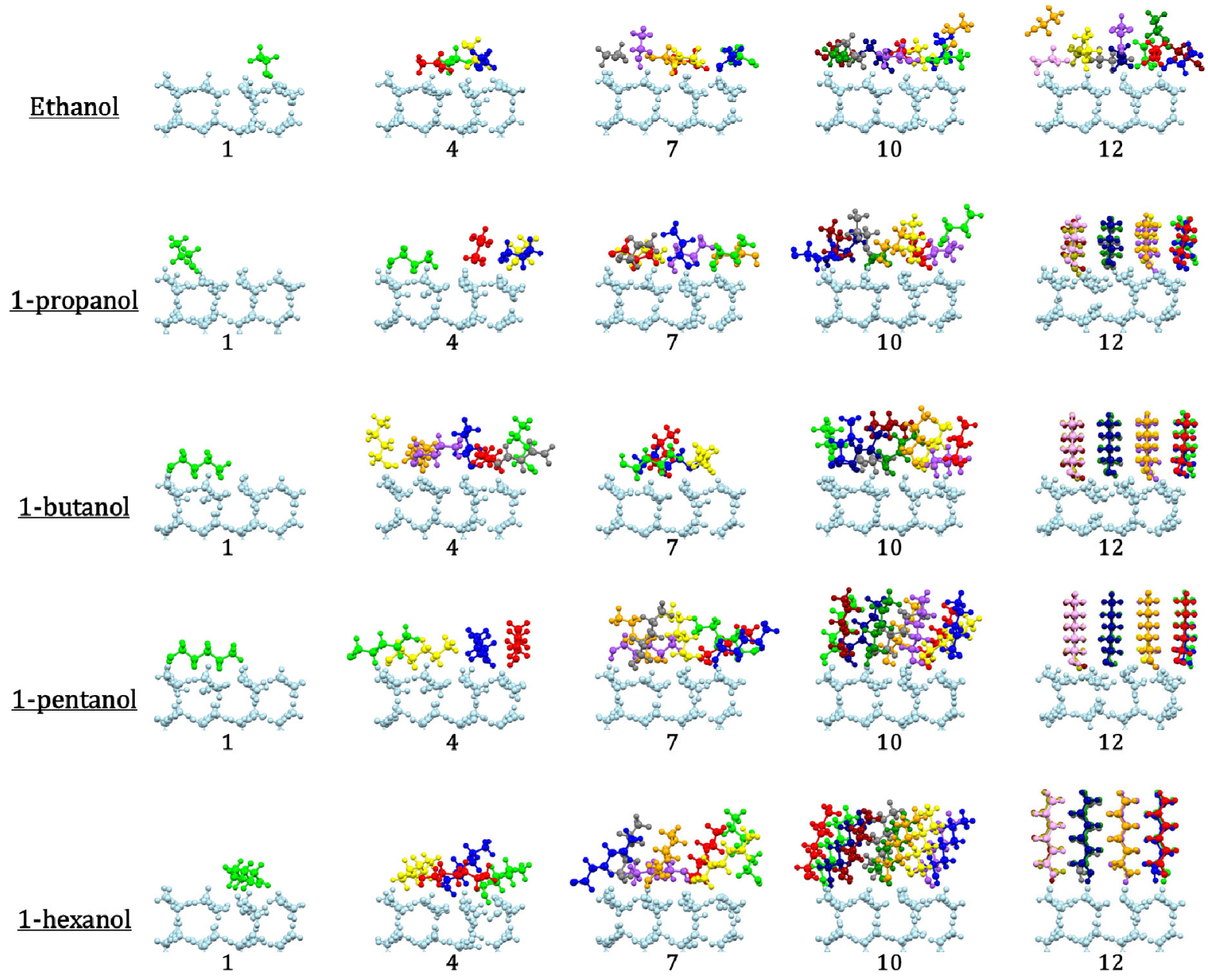

Acetic acid
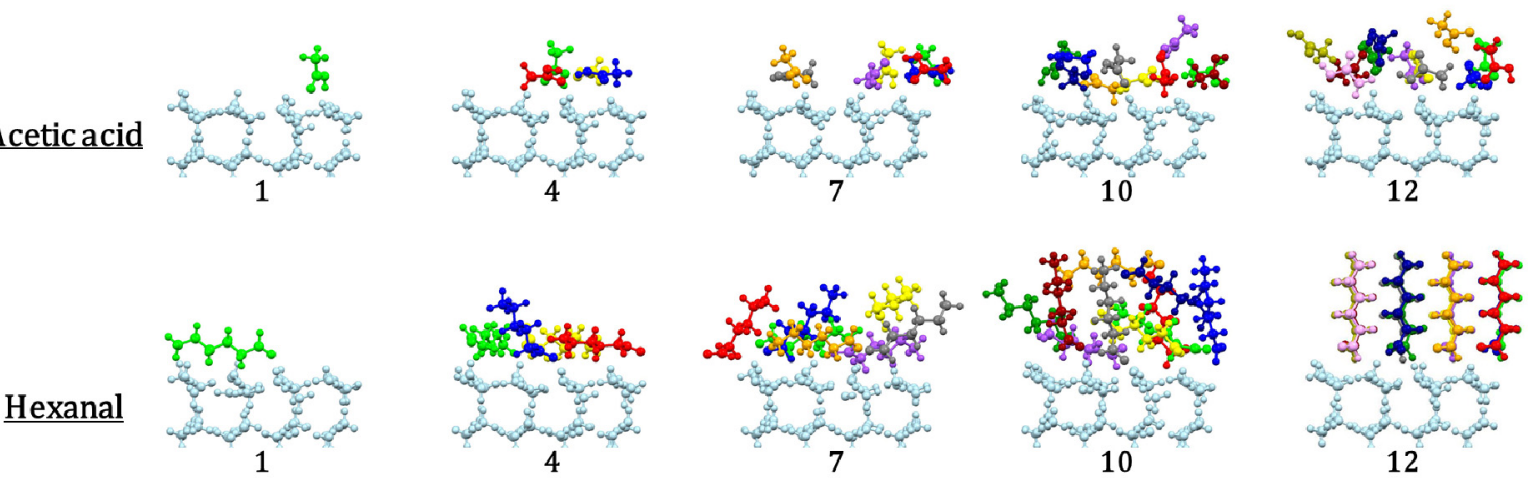

Figure S2. Optimized structures of the lowest energy minimum for the adsorption of $M=1,4,7$, 10, and 12 guest molecules, a side view (100). 
Ethanol
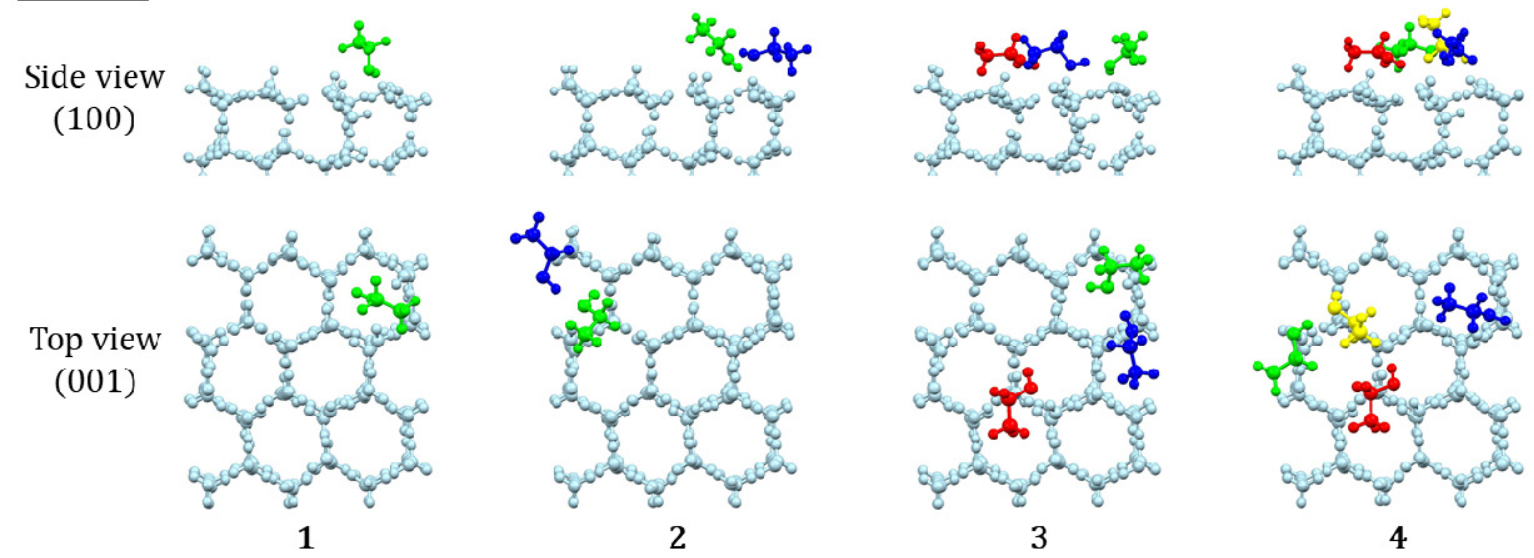

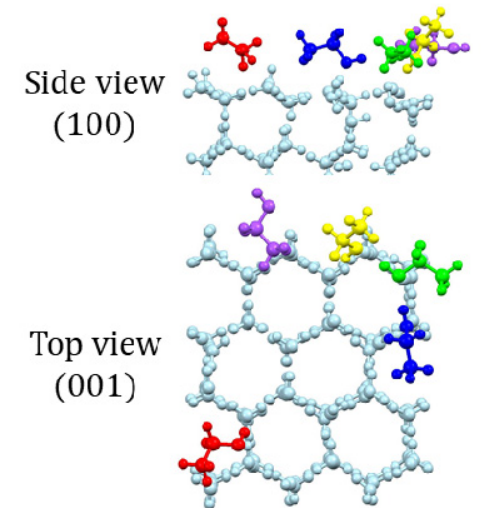

5

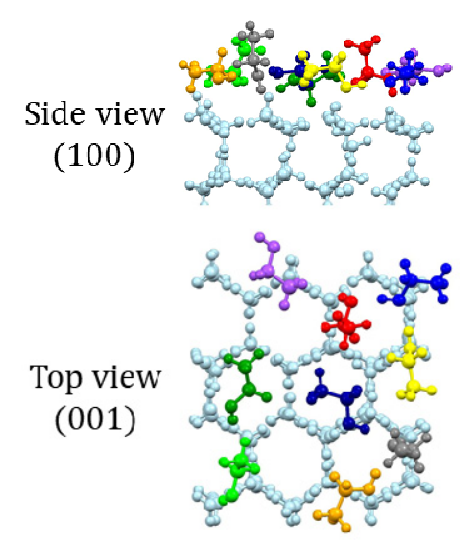

9
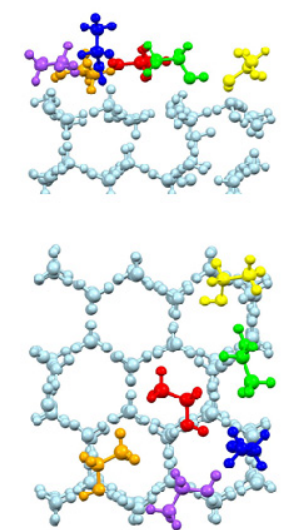

6
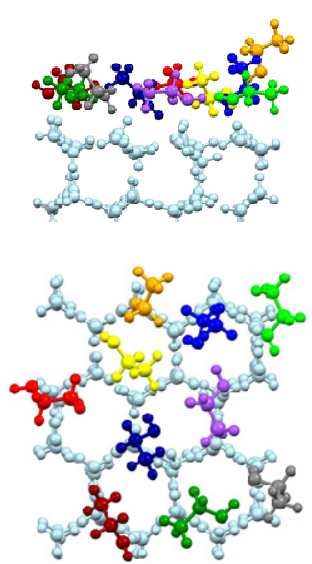

10
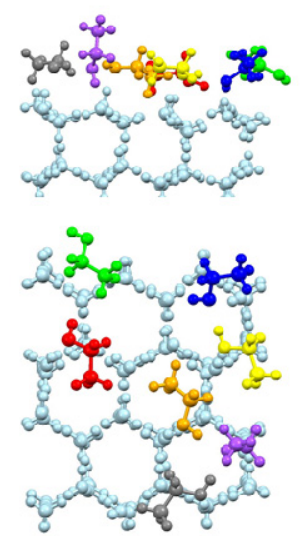

7
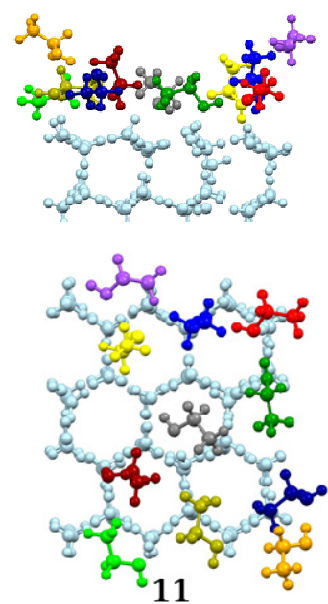
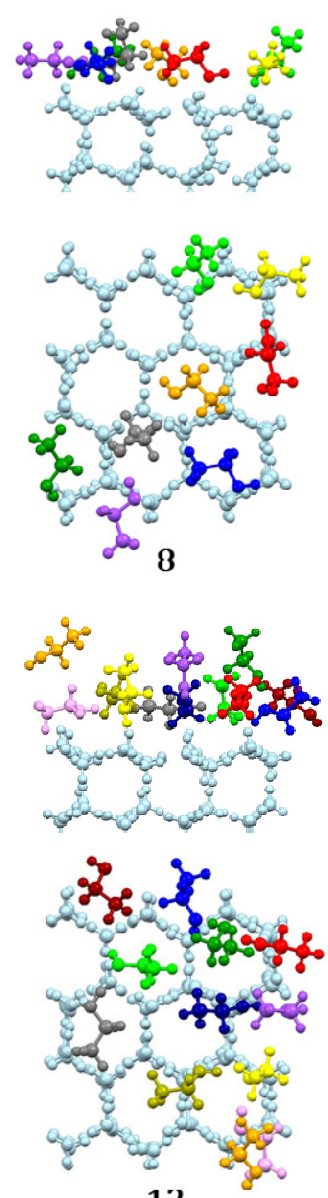

12

Figure S3. Structure of the lowest energy minimum for the adsorption of 1-12 ethanol molecules.

Water molecules composing ice surface are in light blue, and ethanol is shown in different colors. 

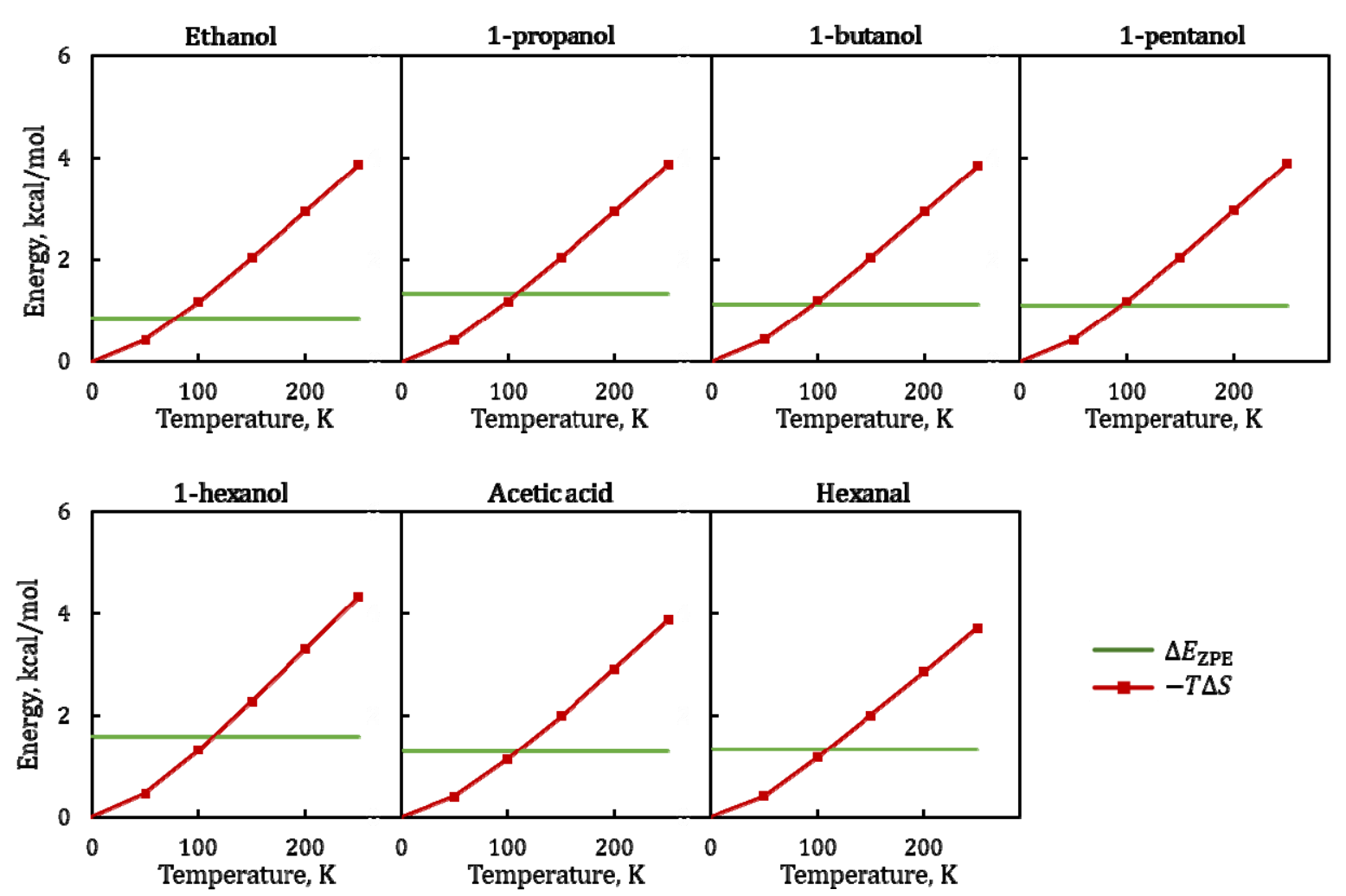

Figure S4. Zero point energy (ZPE) and the energy contribution from entropy $(-T \Delta S)$ for the binding of guests to ice surface.

The magnitude of the 6 ignored lowest vibrational frequencies was typically $0-50 \mathrm{~cm}^{-1}$.

References

(1) Rötger, K.; Endriss, A.; Ihringer, J.; Doyle, S.; Kuhs, W. F. Lattice Constants and Thermal Expansion of $\mathrm{H}_{2} \mathrm{O}$ and $\mathrm{D}_{2} \mathrm{O}$ Ice Ih Between 10 and $265 \mathrm{~K}$, Acta Cryst. 1994, B50, 644-648.

(2) Hayward, J. A.; Reimers, J. R. Unit Cells for the Simulation of Hexagonal Ice. J. Chem. Phys. 1997, 106, 1518-1529. 